\title{
Leadership as a Life Skill in Strengthening the Culture of Educational Institutions
}

\author{
Ms. Mavra Shuaib \\ Research Scholar (Ph.D.), Amity Institute of Education, Amity University Uttar Pradesh, \\ Lucknow,India, mavrashauib@gmail.com \\ Dr. Sushanta Kumar Roul \\ Professor, Amity Institute of Education, Amity University Uttar Pradesh, Lucknow, India \\ skroul@lko.amity.edu

\section{Dr. Rashmi Soni} \\ Associate Professor\& Head, Department of Education, Shri JNPG College, Lucknow, India \\ rashmi_psychologist2003@yahoo.co.in
}

\begin{abstract}
Leadership is regarded as the prime factor for making improvements in educational institutions effectively and also facilitates the achievement of desired goals and objectives and making improvements in the system of education. It is one of the main factors linked with the achievement and failure of any organization. Leadership style is the way in which people are directed and motivated by a leader to attain organizational goals. Life skills are defined as "a group of psychosocial competencies and interpersonal skills that help people make informed decisions, solve problems, think critically and creatively, communicate effectively, build healthy relationships, empathize with others, and cope with and manage their lives in a healthy and productive manner. This study is based on the impact of leadership as a life skill in educational institutions. With the viewpoint of the school, the leadership of the principal is very important. His role and duties will affect all aspects of school organizational life. At the school organizational level, leadership of the principal is the main determinant which act as a link between the individual lives with the outlooks of any organization in the future. This study aims to how leadership as a life skill impacts the performance of educational institutions. This paper is a conceptual based paper which gives theoretical verification to support the idea. The results of the paper suggest that the leadership style is a strong element in enhancing the performance of any institution as it enhances the culture of the organization and the employees'values in the organization.
\end{abstract}

Keywords: Life skill, Leadership, Transactional Leadership, Transformational Leadership, Organizational Culture, Employee Values, Leadership roles. 


\section{Introduction}

Leadership is regarded as the prime factor in making improvements in school effectiveness. Leadership facilitates the achievement of desired goals and objectives and making improvements in the system of education (Educational Leadership, 2017). The role of leadership in an organization is vital in terms of creating a vision, mission, courage and establishment of objectives, designing strategies, policies, and methods to achieve the organizational objectives successfully and capably along with directing and coordinating the efforts and organizational activities (Xu \& Wang, 2008). Top quality leadership is important to achieve the mission and vision along with coping with the changes occurring in the external environment (Harris, et al., 2007). There are several types of leadership styles such as transformational leadership, transactional leadership, autocratic, democratic leadership, participative leadership style, etc.

The employees of the organizations are more aware, educated, and knowledgeable and expecting better values for themselves on the other hand organizations also want to better utilize them to get maximum benefits. Employees' dedication with the organization reduces their intentions to leave the organization and remains the part of organization to work with more efficiently and proper devotion (Pascal et al, 2011). If the workforce is not committed in the organization, then Job insecurity, low trust, high stress and uncertainty will increase in the organization, which have ultimately negative impact on the performance of the organizations (Panayiotis et al, 2011). Organization dedication can also increase the creativity in the organizations (Carlos and Filip, 2011). Societal culture has also impact on the leadership style of the management so that the leadership style in the organization may vary from society to society (Mujtaba et al, 2011). For the better performance of the organization, organizational dedication is one of strong element of success which is highlighted various times in the past literature (Chew and Chan, 2008, Das, 2002). Leadership and its effectiveness is main focus for profit organization to achieve the organizational goals and to create organization commitment in their employees, for their organizations.

Different researchers and scholars presented different theories regarding the leadership efficacy and its relationship to organizational performance in early days (Blake and McCanse, 1991). They mainly focus on the narrow aspects of leadership style including transactional leadership and transformational leadership (Burn, 1978; Bass, 1985).

Many past studies cover different areas of leadership and its relationship with organizational performance. Swanepoel, Eramus, Van Wyk and Scheck (2000) describe that organizational performance is encouraged with the leadership style. Research conducted on the leadership style and its relationship with organizational performance (Lo, Ramayah\& Min, 2009) concluded that transactional and transformational leadership positively correlated with organizational unity. Lo, Ramayah, Min \& Songan (2010) conducted the research on the leadership style and organizational commitment, he states that conflict can be reduce between the leader and subordinate when culture reflect the employee values. The study investigates the relationship of employee value with organizational culture and how to incite a sense of 
commitment in employee to increase the level of attachment with the organization which reduces the employee turnover. Dedication towards work smooth's the process of achieving organizational goals and objectives.

\section{Leadership style}

Leadership style is viewed as an arrangement of different characteristics, traits and behaviours that are used by leaders for interacting with their subordinates. (Mitonga-Monga \& Coetzee, 2012). Mitonga Monga and Coetzee (2012) consider leadership as the outline associated with managerial behaviour, which is intended to integrate the organizational or personal interest and effects for achieving particular objectives.

\section{Transactional Leadership:}

Transactional Leadership is a type of leadership style which is commonly used in behaviour sciences. The founder of transactional leadership is Burns (1978) that describe the transactional leadership as exchange the relationship between leader and subordinates. Major focus of transactional leaders is follower role clarification and leaders have to know about the needs of employee to fulfil the goals. Bass and Stogdills (1990); and Avolio et al. (2004) examine the attributes of the transactional leadership in two ways, first is contingent rewards and second is management by exception. Hellriegel and Slocum, (2006) explain that transactional leadership based on three primary components; contingent reward, active management by exception and passive management by exception. In contingent reward, transactional leader provide reward in exchange of achieving targets and these targets are set on the basis of short-term goals. In active management by exception, leader observes the subordinate performance and eliminates the difference of subordinate from the path of goal. In passive management by exception, transactional leader interacts in the matter of employee when subordinate give unaccepted performance.

\section{Transformational Leadership:}

Transformational leadership is an effective leadership for school administrators. It renders a significant contribution in transforming the individuals into future leaders by making provision of control to them over their behaviours and personality traits. In order to assume leadership roles, it is essential for the individuals to generate awareness and augment their competencies, so they can perform their job duties in a well-organized manner. Within the educational institutions, it is vital for leaders to form a culture that would lead to emergence of leadership skills not only among the heads and educators, but also among students. It is essential for educators to make provision of knowledge and information that would enable them to implement leadership skills in an operative manner. Culture building is focused upon in educative leadership (Tng, 2009).

\section{What are life skills}

Life skills are flexibility, initiative, social skills, productivity, and leadership. Leadership is a group of related skills that combines the other life skills. Good leaders take initiative, have strong social skills, are flexible, and are productive. They also identify goals, inspire others to 
share those goals, organize a group so that all members can contribute according to their abilities, resolve conflicts among members, and encourage the group to reach their goals, help group members solve problems and improve performance, give credit where it is due.

\section{Leadership Roles}

The leaders particularly in higher educational institutions, where the students are adults need to recognize their roles. It is comprehensively acknowledged that adults are more responsible and recognise their job duties well. They assign priorities and ensure they carry out all tasks and activities and devote sufficient amount of time towards them. In the implementation of leadership roles, there are certain aspects, which need to be taken into consideration. These are, in adult education, the leaders put in sufficient amount of time and work diligently and resourcefully. Within the course of pursuance of academic programs, it is vital for students to conduct research on a regular basis and update knowledge and information. The activities and functions of the leaders are dominated by the issues and events of the system of which they are a part. Leaders need to ensure that within the course of performance of job duties, they do not experience any barriers. Hence, it is vital for them to put into operation, the measures and approaches to overcome barriers.

Leaders possess strong viewpoints and perspectives regarding the attainment of the purpose of the system. They possess strong feelings in terms of achievement of desired goals and objectives (Sergiovanni, 1982). In order to carry out one's job duties satisfactorily, it is essential to generate information in terms of various aspects that would render an important contribution in upgrading the structure of educational institutions and the overall system of education. When the leaders are carrying out their roles, they need to ensure they not only make use of their educational qualifications, skills and abilities to promote well-being of the educational institutions and facilitate the achievement of academic goals and objectives, but also their efforts and undertakings need to bring about community welfare. In order to acquire efficient understanding of how leaders are rendering an important contribution towards leading to progression of the community and nation, it is essential to understand leadership roles. The leadership roles are classified into three main categories. These are, interpersonal, informational and decisional. (Chapter -1. Leadership Concept and Theories, n.d.).

\section{Interpersonal Roles}

In interpersonal roles, the leaders need to take into consideration, three kinds of roles, these are, figurehead, leader and liaison. In all these roles, they are required to deal with other individuals. The heads and educators first need to serve as figureheads. In their roles as figureheads, they are required to act as true mentors, which may participate effectively in leading and guiding the students in the right direction. They not only help their students or subordinates to achieve goals and objectives, but also guide them in inculcating the traits of diligence, resourcefulness and conscientiousness and emerging into effective citizens of the country. The interpersonal roles of the leaders are focused on providing knowledge and information to the individuals in an appropriate manner and ensuring they develop interest and motivation towards the implementation of their job duties. 
In the interpersonal role of liaison, the leaders ensure they facilitate co-operation and association between individuals. For instance, when individuals get engaged in a conflicting situation or a disagreement and approach their leaders, it is the job of the leaders to settle the dispute peacefully and enable the individuals to form good terms and relationships with each other. It is of utmost significance for students to form good terms and relationships and work in collaboration and integration with each other to produce the desired academic performance. In the role of a liaison, the leader acts as a link or a co-ordinator between people, groups and organizations.

\section{Informational Roles}

In informational roles, the leaders carry out three kinds of roles. These are, roles of monitor, disseminator and spokesperson. In the implementation of these roles, they are required to get involved in the processing of information. When the individuals are carrying out these roles, they are placed at the strategic point to gather and disseminate information. As a monitor, the leader is seeking information that may be valuable and worthwhile to the organization. He questions the other individuals, primarily the ones, whom he is monitoring. The primary job duties of the monitor are to ensure that discipline is maintained and individuals are performing their job duties in an appropriate manner.

As the disseminator of information, the relevant information is transferred to others within the working environment. As the term implies, disseminating of information means distributing information. When the leaders are aware of important information, it is their job to ensure that it is adequately transmitted to others. Making provision of timely information to others is regarded as an important aspect in leading to proper functioning of the educational institutions. The third informational role of the spokesperson focuses upon communication. As a spokesperson, the leaders are required to communicate effectively with the other individuals, make provision of adequate information and guide and lead them in the right direction.

\section{Decisional Roles}

The decisional roles that have been identified are four. These are, entrepreneur, disturbance handler, resource allocator and negotiator. The entrepreneur roles of the leaders focus upon putting into operation, modern and innovation methods and approaches that may lead to effective outcomes. As entrepreneurs, they need to upgrade their improvisation skills and abilities. The role of the leaders as disturbance handlers focuses upon handling disturbances and problems that may occur within the course of implementation of job duties and functioning of the educational institutions. In some cases, students or other members of the educational institutions may get involved in the conflicting situations or disagreements. Therefore, it is the job of the leaders to ensure, they get resolved peacefully and members of the educational institutions and fellow students establish good terms and relationships with each other.

The role of the leaders as resource allocator focuses upon the fact that there are availability of adequate materials, equipment and technologies, which may render an effective contribution in facilitating learning among individuals and enabling them to achieve the desired goals and 
objectives. In order to facilitate the teaching-learning processes, it is necessary to ensure adequate materials and resources are available. As negotiators, the leaders ensure that the overall atmosphere within the working environment remains pleasant and amiable. They need to possess effective communication skills and ensure members work in co-ordination with each other.

\section{Organizational Culture:}

Hofstede define culture as software of the mind that helps in our daily interaction. The way of feeling and thinking of each person is different from others. Lewis cultural model has three division which are multi-active, linear active and reactive. The multi-active set includes family, relationship, loyalty and emotion while linear active include facts, planning, product and law. The reactive part included courtesy, face, collective harmony and common obligation. Edgar Schein's model of culture included in three parts artifacts, espouse values and assumptions. Iceberg cultural model is used to give better understanding of behaviour. The strong culture has positive effect on the behaviour of subordinates and it increase the commitment and performance between them which is good for institution while weak culture has negative impact on the performance and employees of the institute. Therefore, in weak culture, there is need to improve their behaviour and expression in direction of institution's culture.

\section{Employee Values:}

Employee value means the outlook of an employee from its employer against its input and performance. Efficient employee values help the institution to maximize the performance of the employees, retains the loyal workforce, reduce new hire premium and attract the talent for the organization (Talentsoothie, 2010). Attributes and benefits lays positive effect on the motivation of the candidates so that they will have a preference to work for the organization and existing employees will stay in the organization. CLC (Corporate leadership council) gives the following attributes of Employee value proposition.

- Reward

- Constancy

- Growth opportunities

- Future career opportunities

- Admiration

- Administrator quality

- Collegial work environment

\section{Organizational Performance}

Organizational Performance is a multifaceted and multidimensional phenomenon in the business literature. Organizational performance comprises of the results of an organization, which can be considered against intended outputs, goals and objectives. 


\section{Methodology}

This paper aims to present a conceptual understanding through literature reviews. The concept is that how leadership as a life skill Strengths the culture of Educational Institutions. After defining all the main variables of this study theoretical evidences proves that employees' values are the element of organization culture and organization culture is influenced by the leadership style of the organization. Paper provides link between leadership style and organization commitment and shows that how organization commitment can be increased by leadership style, when organization culture reflects the values of the employees.

\section{Discussion}

Effectiveness of the organization or institution relies on the leadership style in the organization through communicating policies and plans, rules and regulations, offering incentives, instructions, co-operation and build well-organized work environment which facilitates the employees in a positive way. The founder of transactional leadership is Burns (1978) which describes the transactional leadership as exchange of relationship between leaders and subordinates. Transactional leadership gives benefit at the accomplishment of goals while penalties at not achieving the targets. Hellriegel and Slocum, (2006) describe that transactional leadership has three parameters; contingent reward, management by exception (active) and management by exception (passive). The Burn's theory of transformational leadership explained that leader has more moral quality and leader scarifies his own interest over the group interest. Avolio and Bass in 1988 and 1994 classify the leadership skills into 4 I's including Idealized influence, Inspirational motivation, Intellectual stimulation and Individualized consideration.

\section{Leadership Style and Organizational Culture:}

Organizational culture is a main element of employee motivation and commitment which improves the organization performance. Previous literature on the leadership relationship with the culture reveals many forms of behaviour and attitude which based on culture environment. This variation comes from the different workforce ideas (Bass, Jung and Avolio; 1999 \& Yamaguchi, 1999) and also leadership style varies from culture to culture (Dorfman et al, 2004; wood and Jogulu, 2006). Bass (1985) conducted study on leadership style and its impact on culture and found that transactional leader's function in a boundary of existing culture, while transformation leaders work to align the culture of the organization with vision of the organization. Schein (1992). Organizational culture reflects the values and beliefs of founder and shaped the traits of organization. Hartog, Muijen and Koopman (1997) provide a link between transactional and transformational leadership with the culture and found positive relationship between leadership style and organization culture. Organizational culture and leadership depend on each other and leader develops the values, norms and behaviours of employees within culture (Bass and Riggio, 2006). Jogulu (2010) found that leadership style changes as the culture of the organization changes. 


\section{Leadership Styles and Organizational Performance}

There is a considerable impact of the leadership styles on organizational performance. The leadership style influences the culture of the organization which, in turn, influences the organizational performance. Klienet al (2013) proved this fact by using four factor theory of leadership along with the data collected from 2,662 employees working in 311 organizations. The organizational culture and performance are related to the type of leadership style (Klein, et al., 2013). Transformational leadership style focuses on developing the followers and considering their needs. The managers that focus on transformational leadership focus particularly on developing the overall value system of the employees, development of moralities, skills and their motivation level. Bass and Avolio (1994) stated that transformational leadership demonstrates the superior leadership performance. The personalized relationship developed by a transformational leader develops an environment in which the employees feel happy and hence, their overall performance is improved. Hence, it can be said that transformational leadership and organizational performance are positively associated (Jyoti \&Bhau, 2015).

A leader is known as a transactional leader if he/she is always willing to give something in return (Uchenwamgbe, 2013). This can include a number of things like promotion, pay raise, performance reviews, new responsibilities etc. The major problem with this type of leadership is the expectation. Hence, transactional leadership can be defined as the exchange of targets and rewards between the management and the employees (Ojokuku, et al., 2012). This leadership style particularly helps in creating an environment that is optimal for performance and also articulates the compelling vision that enhances the overall organizational performance (Longe, 2014).

\section{Conclusion}

Educational institutions have to build up strong culture in their workplace for success. Strong culture can be developed by the leadership which is a strong element of life skill that increases the organizational performance better. Leader can control the employee with the planning and coordination to maintain organizational culture. Leader can get rid of that uncertainty and improve their commitment through establishing organizational culture and employee values must be the main part of this culture. Leader can maintain the organizational culture which reflects the employee value proposition in the organization for the beneficial goals. When organizational culture and employee value proposition are same, it increases the performance of the employees. The major role of employee values and strong organizational culture in the relationship of leadership style and organizational commitment help the organization in maintaining the organisational performance and attract more talented people and retain the existing employees in the organization. So, for that purpose the effort that should be made by a principal leader must be able to notice on improving the quality of performance in educational institutions, improvement in school institutions is not possible without focusing on educational leadership style maintain by the principal. 


\section{References}

Avolio, B. J. \& Bass, B. M. (1994). Improving organizational effectiveness through transformational leadership. California: Sage.

Avolio, B. J., \& Bass, B. M. (1988). Transformational leadership, charisma, and beyond. In J. G. Hunt, B. R. Baliga, H. P. Dachler, \& C. A. Schriesheim (Eds.), Emerging leadership vitas (29-49). Lexington, MA: Lexington Books.

Avolio, B. J., Bass, B. M., \& Jung, D. I. (1999). Re-examining the components of transformational and transactional leadership using the Multifactor Leadership Questionnaire. Journal of Occupational \& Organizational Psychology, 9(72), 441462.

Avolio, B. J., Zhu, W., Koh, W. L., \& Bhatia, P. (2004). Transformational leadership and organizational commitment: Mediating role of psychological empowerment and moderating role of structural distance. Journal of Organizational Behavior, 25, 951 968.

Bass \& Avolio, 1994. Improving Organizational Effectiveness Through Transformational Leadership. London: SAGE Publications.

Bhargavi, S. \& Yaseen, A., 2016. Leadership Styles and Organizational Performance. Strategic Management Quarterly, 4(1), pp. 87-117.

Blake R. \&McCanse, A. (1991). Leadership dilemmas-Grid solutions. Grid management and organizational development, Gulf Co.

Burns, J. M. (1978). Leadership. New York: Harper \& Row.

Carlos, M. P. \& Filipe, C. (2011). From personal values to creativity: evidence from frontline service employees. European Journal of Marketing, 45 (7/8), 1029-1050.

Chew, J. \& Chan C. C. (2008). HR practices, Organizational Commitment and intention to stay. International Journal of Manpower, 29(6), 503-522.

Chapter -1. (n.d.). Leadership Concept and Theories. Retrieved October 18, 2019 from https://shodhganga.inflibnet.ac.in/bitstream/10603/124054/9/09_chapter\%201.pdf

Educational Leadership. (2017). Cambridge Assessment International Education. Retrieved October 17, 2019 from https://www.cambridgeinternational.org/Images/271192educational-leadership.pdf

Harris, A. et al., 2007. Distributed leadership and organizational change: Reviewing the evidence. Journal of Educational Change, 8(4), pp. 337-347.

Jyoti, J. \& Bhau, S., 2015. Impact of transformational leadership on job performance: Mediating role of leader- member exchange and relational identification. SAGE Open, 5(4), pp. 1-13.

Klein, A. S., Cooke, R. A. \& Wallis, J., 2013. The impact of leadership styles on organizational culture and firm effectiveness: An empirical study. Journal of Management \& Organization, 19(3), pp. 241-254.

Longe, O. J., 2014. Leadership style paradigm shift and organisational performance: A case of the Nigerian Cement Industry. African Research Review, 8(4), pp. 68-83.

Mitonga-Monga, J. \& Coetzee, M., 2012. Perceived leadership style and employee participation. African Journal of Business Management, 6(15). 
Mujtaba, G. B., Afza, T. \& Habib, N. (2011). Leadership Tendencies of Pakistanis: Exploring Similarities and Differences based on Age and Gender. Journal of Economics and Behavioral Studies, 2(5), 199-212.

Ojokuku, R. M., Odetayo, T. A. \&Sajuyigbe, A. S., 2012. Impact of leadership style on organizational performance: a case study of Nigerian banks. American Journal of Business and Management, 1(4), pp. 202-207.

Panayiotis, S., Pepper, A. \& Phillips, M. J. (2011) Transformational change in a time of crisis. Strategic HR Review, 10 (5), 28-34.

Parry, K. W. (1998). Grounded theory and social process: A new direction for leadership research. Leadership Quarterly, 9, 85-105.

Pascal, P., Pierre-Sébastien, F. \& Lamontagne, S. (2011). Relationships between commitments to the organization, the superior and the colleagues, and the intention to leave among trucker. International Journal of Organizational Analysis, 19(2), 92-108.

Sergiovanni, T. J. (1982). Ten Principles of Quality Leadership. Retrieved October 17, 2019 from http://www.ascd.org/ASCD/pdf/journals/ed_lead/el_198202_sergiovanni.pdf

Tng, C.S. (2009). An Educational Leadership Framework Based on Traditional and Contemporary Leadership Theories. Retrieved October 17, 2019 from https://www.g-casa.com/PDF/malaysia/TNG.pdf

Vigoda-Gadot, E., 2012. Leadership style, organizational politics, and employees' performance: An empirical examination of two competing models. American Journal of Business and Management, 36(5), pp. 661683.

Xu, G. Y. \& Wang, Z. S., 2008. The impact of transformational leadership style on organizational performance: The intermediary effects of leader-member exchange. Long Beach, CA, USA, IEEE Xplore, pp. 1090-1097. 